\title{
PADRÕES DE CARREIRA EM MULTI-LEVEL SYSTEMS: O CASO DOS VICE-PREFEITOS DAS CAPITAIS ESTADUAIS DO BRASIL
}

Nilton Sainz ${ }^{1}$

\begin{abstract}
Resumo
Este estudo tem como objeto de análise a carreira eleitoral dos vice-prefeitos das capitais estaduais do Brasil eleitos entre 1985 e 2012. O objetivo desta pesquisa é investigar a circulação dos políticos profissionais no decorrer de suas carreiras eleitorais, observando as decisões tomadas por eles. Desta forma, busca-se responder a seguinte pergunta: quais padrões de carreira eleitoral apresentam os vice-prefeitos das capitais estaduais brasileiras, após eleitos ao cargo? Através do banco de dados do TSE e TREs foram coletados os dados eleitorais. A análise fez uso de cálculos de estatística descritiva e correlações simples de variáveis. Os resultados desta investigação reafirmam a existência de padrões de carreira eleitoral integrados. Isso significa que as escolhas de carreira dos vice-prefeitos das capitais do Brasil não são unidirecionais ou rígidas, suas ambições políticas variam com frequência em relação ao poder político, nível de governo e ao cargo eletivo ambicionado. Em suma, o estudo contribui para compreender as escolhas de carreiras a partir de um posto eletivo que possui baixo capital político, podendo ser considerado de "segundo escalão" da política brasileira.
\end{abstract}

Palavras-Chave: Padrões de carreira; Ambição política; Vice-prefeitos; Multi-level systems.

\section{INTRODUÇÃO}

Assim como qualquer profissão, a política é permeada por oportunidades para aqueles que desejam seguir carreira. Algumas dessas chances representam crescimento e requerem que os atores disponham de maiores recursos para obter sucesso em suas trajetórias. Já outros passos, vão demandar menores recursos, ao mesmo tempo que representam menores ganhos na carreira.

O objeto de investigação desse trabalho são as carreiras eleitorais dos vice-prefeitos das capitais estaduais do Brasil eleitos entre 1985 e 2012. Essa pesquisa busca respoder a seguinte pergunta: quais os padrões de carreiras eleitorais apresentam esses atores após eleitos ao cargo de vice-prefeito?

Nesse sentido, buscou-se examinar a carreira eletiva desses atores a partir de três momentos: a) carreira eleitoral anterior ao cargo, ou seja, se os vice-prefeitos possuem ou não experiência prévia em cargos eletivos; b) continuidade na carreira eleitoral após eleitos para o cargo de viceprefeito; c) os impactos da estrutura de oportunidade do sistema político frente as escolhas de

\footnotetext{
${ }^{1}$ Doutorando em Ciência Política pelo Programa de Pós-Graduação em Ciência Política da Universidade Federal do Paraná. Bolsista CAPES. E-mail: sainznilton@gmail.com. ORCID: https://orcid.org/0000-0002-3957-2714
} 
carreiras durante e no fim do mandato, verificando para onde vão esses atores na $1^{\circ}, 2^{\circ}$ e $3^{\circ}$ oportunidade de disputar um novo posto eletivo.

Para além dessa introdução, a estrutura desse paper está em seis seções. A seção a seguir apresenta um breve panorama da problemática dos "vices" no Brasil, trazendo para o trabalho a discussão em relação aos cargos de vice no país e as questões que permeiam o debate. A terceira seção busca inserir ao trabalho as principais contribuições da Ciência Política sobre padrões de carreira política no Brasil e relacionar com o problema de pesquisa proposto. A quarta seção apresenta a metodologia aplicada à pesquisa, com suas principais escolhas. A quinta segue com os resultados e as análises a partir dos dados obtidos pela pesquisa. E a sexta traz as considerações finais do texto apresentado.

\section{O CASO DOS "VICES": DAS POLÊMICAS AOS SIGNIFICADOS DO CARGO}

Os significados dos cargos de vice no Brasil são pouco explorados em diversas frentes. Em termos constitucionais, com base do Art. 79, a definição do cargo de Vice-Presidente da República se resume a função de um substituto em caso de morte ou impedimento do Presidente da República, além de poder cumprir outras atribuições que são conferidas pelo Presidente, como auxiliar em missões especiais (BRASIL, 1988). No entanto, a definição é amplamente vaga para compreender o papel desse ator em um governo ou sistema político.

Assim como outras áreas do conhecimento, a Ciência Política brasileira também volta sua atenção para compreender a Vice-Presidência da República ou os atores que já passaram pelo posto. Essa lacuna chama a atenção, visto que o cargo carrega uma história polêmica no país. Desde o primeiro vice-presidente eleito até os dias atuais, em oito oportunidades o vice-presidente terminou o mandato na função de chefe do Executivo Nacional.

Logo na primeira eleição, que inaugurou a República em 1891, o Vice-Presidente Marechal Floriano Peixoto, através da renúncia do então Presidente Marechal Deodoro da Fonseca, inicia-se a larga história dos vice-presidentes que chegaram a substituir em definitivo o Presidente da República. Desde o então, diferentes contextos e basicamente três motivos concretos levaram os vices ao cargo máximo da República. O Quadro 1 apresenta a relação dos presidentes substituídos, as causas e vice-presidente que assumiu a vaga. 
QUADRO 1 - VICE-PRESIDENTES QUE ASSUMIRAM A PRESIDÊNCIA DA REPÚBLICA NA HISTÓRIA DO BRASIL

\begin{tabular}{|l|l|l|l|}
\hline Presidente da República & \multicolumn{1}{|c|}{ Causa da substituição } & \multicolumn{1}{c|}{ Vice-Presidênte } & \multicolumn{1}{c|}{$\begin{array}{c}\text { Tempo à frente da } \\
\text { Presidência }\end{array}$} \\
\hline Deodoro da Fonseca & Renúncia & Floriano Peixoto & Nov. 1891 a nov. 1894 \\
\hline Afonso Pena & Morte & Nilo Peçanha & Jun. 1909 a nov. 1910 \\
\hline Rodrigues Alves & Morte & Delfim Moreira & Nov. 1918 a jul. 1919 \\
\hline Getúlio Vargas & Morte & Café Filho & Ago. 1954 a nov. 1955 \\
\hline Jânio Quadros & Renúncia & João Goulart & Ago. 1961 a mar. 1964 \\
\hline Tancredo Neves & Morte & José Sarney & Mar. 1985 a mar. 1990 \\
\hline Fernando Collor & Renúncia / Impeachment & Itamar Franco & Out. 1992 a dez. 1994 \\
\hline Dilma Rousseff & Impeachment & Michel Temer & Ago. 2016 a dez. 2018 \\
\hline
\end{tabular}

Fonte: Elaboração própria com base em DHBB (2001) e CPDOC-FGV.

Em 50\% dos casos em que o Presidente da República foi substituído por seu vice, a motivação foi política. Sabendo que a substituição do Presidente da República por seu vice não é algo raro no Brasil e que o fenômeno também acontece a nível municipal, onde 14,6\% dos viceprefeitos das capitais brasileiras eleitos entre 1985 e 2012 assumiram o cargo de Prefeito, é necessário pensar os sentidos desse cargo perante as democracias representativas. Afinal, o que representa na competição política e na composição de um governo um vice?

Primeiramente, é necessário relembrar que para lançar uma chapa em competição eleitoral, é necessário no caso das eleições para Presidente da República, Governador e Prefeito indicar um vice, ou seja, aquele que em caso de necessidade irá substituir o titular, além de poder exercer outras funções caso for demandado. Mas como é realizada essa escolha? O que se sabe a respeito disso?

A nível de investigação concreta, pouco se sabe especificamente sobre o caso brasileiro e o caso latino-americano. Recentemente algumas pesquisas veem sendo desenvolvidas acerca do tema (SARRAFERO, 1999, 2018; MIERES; PAMPÍN, 2015; UGGLA, 2020), porém nenhuma com enfoque voltado ao país. Sarrafero (1999), o primeiro a contribuir com a temática no continente, realiza uma extensa investigação acerca da história dos vice-presidentes na Argentina.

O autor contribui para pensar a figura do vice não apenas como um ator político solidário ao presidente, mas sim um personagem que possui seus interesses e ambições próprias e que nem sempre podem estão alinhadas as ideias do titular (SARREFERO, 1999). Nesse sentido, Uggla (2020) avança no debate, demonstrando que as rupturas e alinhamentos são um fator importante na hora que são formadas as chapas presidenciais na América Latina.

Olhando para os significados do cargo, Sarrafero (1999) diz que o vice cumpre na composição de um governo uma "garantia" de continuidade de um projeto eleito, algo que nem sempre acontece. Como se sabe, uma alteração em meio a um mandato pode significar uma nova 
configuração de ministros ou secretários, além disso, o novo titular pode assumir uma postura diferente em relação as políticas públicas que serão executadas. É relacionado a isso que surge o problema de escolha dos vices e que já provocou alterações na forma de como eram escolhidos esses atores (UGGLA, 2020).

Mieres e Pampín (2015) vão investigar as trajetórias e os processos de seleção dos vicepresidentes na América Latina. Os autores mobilizam uma série de variáveis que podem pesar para a escolha de um vice-presidente, como partido político, gênero, raça, região do país, idade e representatividade social. Segundo os autores, não existe uma aleatoriedade acerca das escolhas de quem é vice-presidente.

É notável que exista uma lógica de mesclar características em relação ao titular e seu vice. A fim de exemplificar para o caso brasileiro, a chapa de Luiz Inácio Lula da Silva um político de origem trabalhista e ligado ao movimento sindical e José Alencar, político com trajetória e ligação nos setores do empresariado brasileiro. No entanto, sabe-se pouco em relação aos impactos dessas mescla de características para a competição política e os respectivos sucessos eleitorais.

Mieres e Pampím (2015) afirmam que essas misturas de características podem variar de acordo com cada país. Porém, sabe-se que essas coligações podem vir a impactar positivamente tanto no momento da eleição, quanto na formação de um governo. Nesse sentido, o vice-prefeito pode somar a uma campanha com HGPE (Horário Gratuito de Propaganda Eleitoral) e diferentes apoios, desde financeiros a setores da sociedade. Além de que no momento da formação de um governo, também pode ser um agente de intermediação entre o Executivo e o Legislativo para realização de negociações.

Voltando a atenção para o cargo de vice-prefeito no Brasil, é possível dizer que o posto possui alguns atrativos para a classe política. O cargo tem a singularidade de ser o único cargo do Executivo na qual é possível o acumulo de função, como por exemplo, além de vice-prefeito, é possível que o político atue na chefia de alguma secretaria municipal. Além disso, o político não precisa abrir mão do mandato para disputar outro cargo público, somente é necessário o afastamento 6 meses antes da eleição.

Todavia, é necessário ressaltar o esquecimento que existe em relação ao cargo. Se alguns fatores interessam a classe política, a baixa visibilidade e até participação em decisões de governo podem ser variáveis que impactam na escolha por não seguir para o cargo. O fato é que muitas vezes o vice-prefeito pouco aparece durante as campanhas eleitorais, o mesmo podendo se repetir 
durante o governo, virando uma espécie de "decoração", algo que pode ser entendido como prejudicial para aqueles que buscam construir uma carreira política, prosseguindo a partir do cargo.

\section{PADRÕES DE CARREIRA POLÍtica NO BRASIL: UM BREVE PANORAMA A PARTIR DO NEOINSTITUCIONALISMO}

Os estudos de carreira política, segundo Costa e Codato (2018), podem se dar através de três correntes principais: a) sociologia da política; b) sociologia política; c) Ciência Política mainstream ou neoinstitucionalismo de escolha racional. Nessa investigação, a atenção estará voltada para essa última.

Com origem na literatura norte-americana, o estudo de Joseph Schlesinger (1966) sobre a ambição política dos congressistas norte-americanos inaugura a corrente. Ao olhar os passos de carreiras posteriores dos políticos profissionais, o autor busca identificar os tipos de ambição política existentes na estrutura de oportunidade proveniente do sistema político dos Estados Unidos.

No Brasil, quem inaugura os estudos acerca das escolhas de carreiras dos parlamentares brasileiros é David Samuels (1999, 2003). O autor, concentrado em compreender as carreiras eleitorais na Câmara dos Deputados, a partir de regras do sistema eleitoral e partidário, busca compreender custos e benefícios dos cargos disponíveis no país. Samuels considera características particulares dos postos eletivos, demonstrando, assim, o que pode ter de atrativo nos cargos. A investigação de Samuels (2003) aponta para a existência de uma hierarquização dos cargos políticos no Brasil, assim como no modelo norte-americano.

Para Samuels (2003), a principal diferença é que o sistema político brasileiro não consolidava carreiras duradouras na Câmara dos Deputados, o que resultava na alta taxa de renovação na casa e, por consequência, baixa institucionalização e profissionalização. Segundo o autor, a ambição política dos parlamentares brasileiros estava principalmente direcionada aos poderes executivos estaduais e municipais. O que justificaria a preferência por esses cargos são os recursos que neles estão concentrados, como o poder de indicação, maior autonomia e maior visibilidade (SAMUELS, 2003), o que deixaria a passagem pela Câmara dos Deputados como uma espécie de trampolim para a continuidade em busca de cargos mais altos em suas carreiras. Devido essa tendência por ambição progressiva, o autor considera que aqueles parlamentares mais fortes 
possuem menores chances de permanecer no Legislativo nacional, tornando assim a instituição um local frequentado por políticos mais "fracos".

Santos (1999) explica que a possível desvalorização do poder Legislativo pela classe política brasileira era marca deixada pela ditadura civil-militar, que enfraqueceu e retirou poder decisório da instituição ao longo dos anos. Diferente de Samuels (1999, 2003), Fabiano Santos (1999) percebe que no Brasil o movimento padrão de carreira era o chamado "zigue-zague", ou seja, não existindo uma única direção de ambição política, mas sim uma circulação entre os níveis de governo e poder político no país. Mais tarde, confirmando essa posição, Santana (2008) apresenta a chamada ambição dinâmica, que caracteriza essa busca por movimentos variados ao longo de suas carreiras.

Em seguida, refutando a tese de Samuels (2003), Leoni, Pereira e Rennó (2003) inserem o conceito de ambição regressiva, na qual marcaria a posição daqueles parlamentares mais fracos, que ao invés de buscar permanecer na Câmara dos Deputados, optariam por descer na hierarquia política com a finalidade de sobreviver no jogo. Além dessa conclusão, os autores percebem que os parlamentares brasileiros estão dispostos a buscar cargos mais altos somente quando possuem recursos para o sucesso eleitoral, do contrario a busca é por permanecer no cargo ou optar pela ambição regressiva, o que vai ao encontro com os achados de Samuels.

Posteriormente, Santos e Pergurier (2011) também refutam a tese do autor brasilianista, demonstrando que a Câmara dos Deputados apresenta crescimento nas taxas de reeleição ao longo dos anos, indicando uma institucionalização e também não significando uma etapa desprezível em suas carreiras, já que pode significar uma passo importante e de crescimento para um político profissional.

Investigando o caso dos países federalistas, Jens Borchert também se soma aos que buscaram compreender os padrões de carreira política no Brasil. O autor inclui o país como um multi-level system, o que significa que a estrutura de oportunidade varia conforme os níveis de governo, formando diferentes ambientes de competição política. Segundo Borchert, os países multiníveis estão caracterizados pela oferta de carreiras políticas separadas por arenas e que possuem suas próprias lógicas de competição, possuindo um amplo repertório de cargos eletivos sendo ofertados (BORCHERT, 2009).

Para os países multiníveis, Borchert (2009) propõe três tipos de movimentos de carreiras nesses sistemas políticos, conforme está descrito no Quadro 2. 
QUADRO 2 - MOVIMENTOS DE CARREIRA EM PAÍSES COM MULTI-LEVEL SYSTEMS

\begin{tabular}{|c|l|}
\hline Movimento & \multicolumn{1}{|c|}{ Característica } \\
\hline Unidirecional & $\begin{array}{l}\text { Movimento de carreira bem definido. Clareza na direção } \\
\text { hierárquica (crescimento) entre os cargos. Velocidade de } \\
\text { movimentos e profissionalização política variam } \\
\text { conforme a estrutura de oportunidade. }\end{array}$ \\
\hline Alternado & $\begin{array}{l}\text { Não prevalece uma única direção de movimentos de } \\
\text { carreira. É possível identificar uma hierarquia de cargos } \\
\text { eletivos. Lenta velocidade nos movimentos de carreira e } \\
\text { alta profissionalização política. }\end{array}$ \\
\hline Integrado & $\begin{array}{l}\text { Movimentos de carreira sem definição de direção. } \\
\text { Múltiplas possibilidades de circulação entre os cargos. } \\
\text { Não existe clareza em relação a hierarquia de postos } \\
\text { eletivos. Velocidade alta entre movimentos de carreira e } \\
\text { altos níveis de profissionalização. }\end{array}$ \\
\hline
\end{tabular}

Fonte: Elaborado própria a partir de Borchert (2009, p.6).

Segundo Borchert (2009, 2011), o Brasil é caracterizado por ter um sistema integrado, onde a frequência nos movimentos de carreira é considerada alta, soma-se a isso o alto número de cargos atraentes para quem deseja obter um cargo eletivo, com possibilidade de disputar um novo cargo em meio ao seu mandato. No entanto, Borchert (2009) alerta para a alta incerteza eleitoral que existe no país.

Nesse sentido, Araújo (2012), Pergurier (2009) e Graça e Souza (2014) investigaram em suas pesquisas, que os movimentos de carreiras entre a Câmara dos Deputados e o salto para o Executivo municipal existe, podendo significar um movimento em zigue-zague (ARAÚJO, 2012), onde o político após o seu mandato retorna a Câmara dos Deputados e colhe benifícios dessa circulação entre níveis (PERGURIER, 2009), ou também como uma estratégia eleitoral, quando a iniciativa de concorrer por outro cargo é utilizada para ganhos futuros na eleição para o Legislativo (GRAÇA; SOUZA, 2014).

Lima (2017) corrobora com aquilo que vinha sendo identificado por Borchert. Segundo a autora é possível assimilar o país com ambiente integrado para circulação da classe política, que apresenta resultados que demonstram a alta frequência entre níveis da federação e alternancia de cargos eletivos. De acordo com essa investigação, os políticos profissionais no Brasil tem inclinação em retornar ao Legislativo durante suas carreiras, porém, interagem com maior frequência com o Poder Executivo, podendo ocupar cargos simultâneos, o que segundo Lima (2017) pode influênciar negativamente na permanencia no Legislativo.

A maioria das pesquisas estão voltas a compreender as carreiras que partem da Câmara dos Deputados. A nível local, as contribuições de Maluf (2006), Lima (2013) e Barreto (2017) podem ajudar a elucidar um pouco mais sobre a dinâmica das carreiras em nível municipal. 
Maluf (2006) e Lima (2013) voltam suas investigações aos vereadores. Assim como a literatura que discorre sobre os deputados federais, essas investigações destacam que os vereadores concorrem em meio ao mandato como forma de "medir temperatura" das urnas, o que pode ser considerado uma característica importante daqueles que ocupam cargos no Legislativo.

Ao olhar o caso da Câmara dos Vereadores da cidade de São Paulo, Maluf (2006) constata que tal instituição apresenta um baixo nível de institucionalização, não possuindo incentivos para carreiras longevas. Segundo ele, a Câmara paulista era formada por dois tipos de políticos profissionais, aqueles amadores, que se retiram da política após um ou dois mandatos, ou os políticos de passagem, que vão em busca de novas ambições na carreira.

Lima (2013) volta sua atenção para os vereadores do Rio Grande do Sul. O autor indica que as maiores tendências de continuidade nas carreiras eleitorais desses indíviduos é rumo ao poder Legislativo estadual. Um achado importante de Lima (2013) é a influência da variável de magnitudade do município, onde aqueles que possuem mais de 100 mil eleitores apresentam um maior número de vereadores dispostos a buscar o cargo de Deputado Federal, representando assim uma ambição progressiva mais elevada.

Em relação ao poder Exevutivo municipal, Barreto (2017) investiga a carreira dos prefeitos das capitais estaduais do Brasil entre os anos de 1996 e 2012. A primeira contribuição de Barreto é identificar que a maioria dos prefeitos das capitais possuem ambições de continuidade na política, a maior parte dos prefeitos das capitais buscam a reeleição imediata ao cargo e escolhem não abrir mão e renunciar do cargo quando estão em segundo mandato. No geral, os prefeitos das capitais se mostraram "bem-sucedidos" nas urnas, apresentando sucesso eleitoral maior que $80 \%$ no caso de reeleição e busca por novos cargos. Contudo, quando ao analisar esses dados desagregados, o sucesso eleitoral desses despenca para 43\%. O que pode ajudar a explicar isso são suas escolhas posteriores de carreira, onde as ambições políticas desses atores são rumo ao Executivo estadual ou Senado Federal, demonstrando com clareza as intenções de ambição progressiva em direção a cargos eletivos bastante acirrados.

\section{MÉTODOLOGIA}

A pesquisa busca compreender a trajetória eleitoral daqueles que foram eleitos ao cargo de vice-prefeito das capitais estaduais do Brasil, no período compreendido pelos anos de 1985 a 2012, 
com vistas a buscar a existência de padrões de carreira política posterior à ocupação de tal cargo do Executivo municipal. Optou-se por investigar aqueles que foram eleitos ao cargo de vice-prefeito e suas carreiras posteriores, ou seja, a continuidade desses atores no jogo político, assim como saber se, efetivamente, buscaram essa continuidade e, consequentemente, se, de fato, tiveram carreira posterior.

O objeto de investigação são todos aqueles que, tendo sido escolhidos por voto direto dos eleitores, assumiram o cargo de vice-prefeito em capitais estaduais do país. Não foram incluídos eventuais vices escolhidos em eleição indireta ou que, eleitos diretamente, renunciaram ou faleceram antes de tomar posse. Considerou-se também aqueles vice-prefeitos que não completaram o mandato no cargo, assim, não foram excluídos do universo de análise aqueles que renunciaram, faleceram, ou deixaram o posto por decisão judicial ou da Câmara de Vereadores.

Em termos de recorte temporal escolhido, o que justifica o começo da investigação em 1985 foi a retomada das eleições diretas nas capitais, consequência do término da ditadura civil-militar que vigorou no país por 21 anos. Já o limite se dá em 2012, tendo em vista serem os eleitos cujo mandato já se encerrou e por conta do número de pleitos realizados após terem sido eleitos (2014, 2016, 2018), o que permite acompanhar um número maior de escolhas de carreiras desses sujeitos que foram examinados. Destaca-se que os vice-prefeitos investigados ingressam no banco de dados e passam a ter a trajetória eleitoral posterior acompanhada no ano em que tomam posse no cargo e a coleta de dados se interrompe na eleição de 2018 ou no ano de falecimento do personagem.

O recorte temporal adotado compreende oito pleitos municipais - 1985, 1988, 1992, 1996, 2000, 2004, 2008, 2012 - e um total de 206 mandatos eletivos de vice-prefeitos. Há atualmente 26 capitais estaduais no Brasil, porém, o estado do Tocantins foi criado pela Constituição de 1988 e sua capital, Palmas, teve a primeira eleição direta em $1992^{2}$. Desse modo, nos dois primeiros pleitos examinados $(1985,1988)$, há 25 vice-prefeitos.

No conjunto, os dados relativos à participação ou não desses vice-prefeitos, os cargos pretendidos e os resultados obtidos, serão coletados para as 18 eleições realizadas no país após 1985 até 2018, que é o processo eleitoral mais recente já transcorrido. Em termos concretos, serão estudados: um pleito isolado para presidente (1989), nove de âmbito nacional-estadual, quando são escolhidos presidente, governadores, senadores, deputados federais e estaduais (1986, 1990, 1994,

\footnotetext{
${ }^{2}$ Foi instalado em $1^{\circ}$ de janeiro de 1990 , com a transformação do então município de Taquarassu do Porto em distrito de Palmas. Como parte desse processo, o prefeito e o vice de Taquarassu do Porto, eleitos em 1988, tornaram-se os titulares do poder Executivo de Palmas até 1993, quanto tomaram posse aqueles foram eleitos diretamente (KAWASAKA FILHO, 2019).
} 
1998, 2002, 2006, 2010, 2014 e 2018) $)^{3}$, e oito de escala municipal, ocasião em que são definidos prefeitos, vice-prefeitos e vereadores (1988, 1992, 1996, 2000, 2004, 2008, 2012 e 2016) ${ }^{4}$.

O Quadro 3 traz sistematizadas as oportunidades que foram geradas ao decorrer dos anos, já relacionando com o alcance da investigação em relação as trajetórias dos vice-prefeitos.

QUADRO 3 - OPORTUNIDADES GERADAS PELO SISTEMA POLÍTICO BRASILEIRO DE 1985 A 2018

\begin{tabular}{|l|l|l|l|l|l|l|l|l|l|l|l|l|l|l|l|l|l|l|}
\hline Eleito & 86 & 88 & 89 & 90 & 92 & 94 & 96 & 98 & 00 & 02 & 04 & 06 & 08 & 10 & 12 & 14 & 16 & 18 \\
\hline 1985 & & & & & & & & & & & & & & & & & & \\
\hline 1988 & & & & & & & & & & & & & & & & & \\
\hline 1992 & & & & & & & & & & & & & & & & & & \\
\hline 1996 & & & & & & & & & & & & & & & & & & \\
\hline 2000 & & & & & & & & & & & & & & & & & & \\
\hline 2004 & & & & & & & & & & & & & & & & & & \\
\hline 2008 & & & & & & & & & & & & & & & & & & \\
\hline 2012 & & & & & & & & & & & & & & & & & & \\
\hline
\end{tabular}

Fonte: Elaboração própria.

Desse modo, quanto mais antigo o momento em que o sujeito foi escolhido vice-prefeito, em teoria, mais oportunidades de concorrer e de obter cargos ele teve. Logo, cada vice-prefeito eleito em 1985 tem a possibilidade de ser acompanhado em, no máximo, 18 eleições. E assim sucessivamente, com redução progressiva da quantidade de observações.

O trabalho relativo a coleta e tratamento dos dados ocorreu em três fases, conforme está descrito no Quadro 4:

\footnotetext{
${ }^{3}$ Para ser mais preciso, deve-se esclarecer que esse elenco de cargos vem sendo eleito concomitantemente desde 1994 , pois em 1986 e em 1990 não houve eleição para presidente.

${ }^{4} \mathrm{O}$ modelo corresponde integralmente aos vices eleitos a partir de 1992 . No caso dos eleitos em 1985 e em 1988 , para que ele prevalecesse, foi preciso realizar adaptações, a seguir explicadas. Os eleitos em 1985 tiveram a $1^{a}$ oportunidade de concorrer em 1986, quando o cargo de presidente não estava disponível; a $2^{a}$ foi o término do mandato, em 1988, que foi mais curto (três anos), a $3^{\text {a }}$ oportunidade efetiva foi a eleição presidencial isolada de 1989 e a $4^{\text {a }}$ correspondeu ao pleito de 1990, quando a oferta compreendia governador, vice, senador, suplentes de senador, deputado federal e deputado estadual. Porém, como nenhum dos vices analisados concorreu em 1989, na prática, considerou-se a eleição de 1990 como a $3^{\text {a }}$ oportunidade. Desajuste semelhante ocorre com os vices eleitos em 1988, cuja $1^{\text {a }}$ oportunidade de concorrer foi o pleito isolado para presidente de 1989 e a $2^{a}$, a disputa de 1990, sendo que o término do mandato, em 1992, coincidiu com a $3^{\text {a }}$ disputa. Assim como no caso anterior, o pleito de 1989 foi suprimido da análise, sendo, na prática, a $1^{\text {a }}$ oportunidade as eleições gerais de 1990 (sem o cargo de presidente), a $2^{\text {a }}$ as municipais de 1992, quando terminou o mandato deles, e a $3^{\mathrm{a}}$, as eleições gerais de 1994, quando além de todos os cargos estaduais-nacionais, também o de presidente foi ofertado.
} 
QUADRO 4 - ETAPAS DE COLETA E TRATAMENTO DE DADOS APLICADAS À INVESTIGAÇÃO

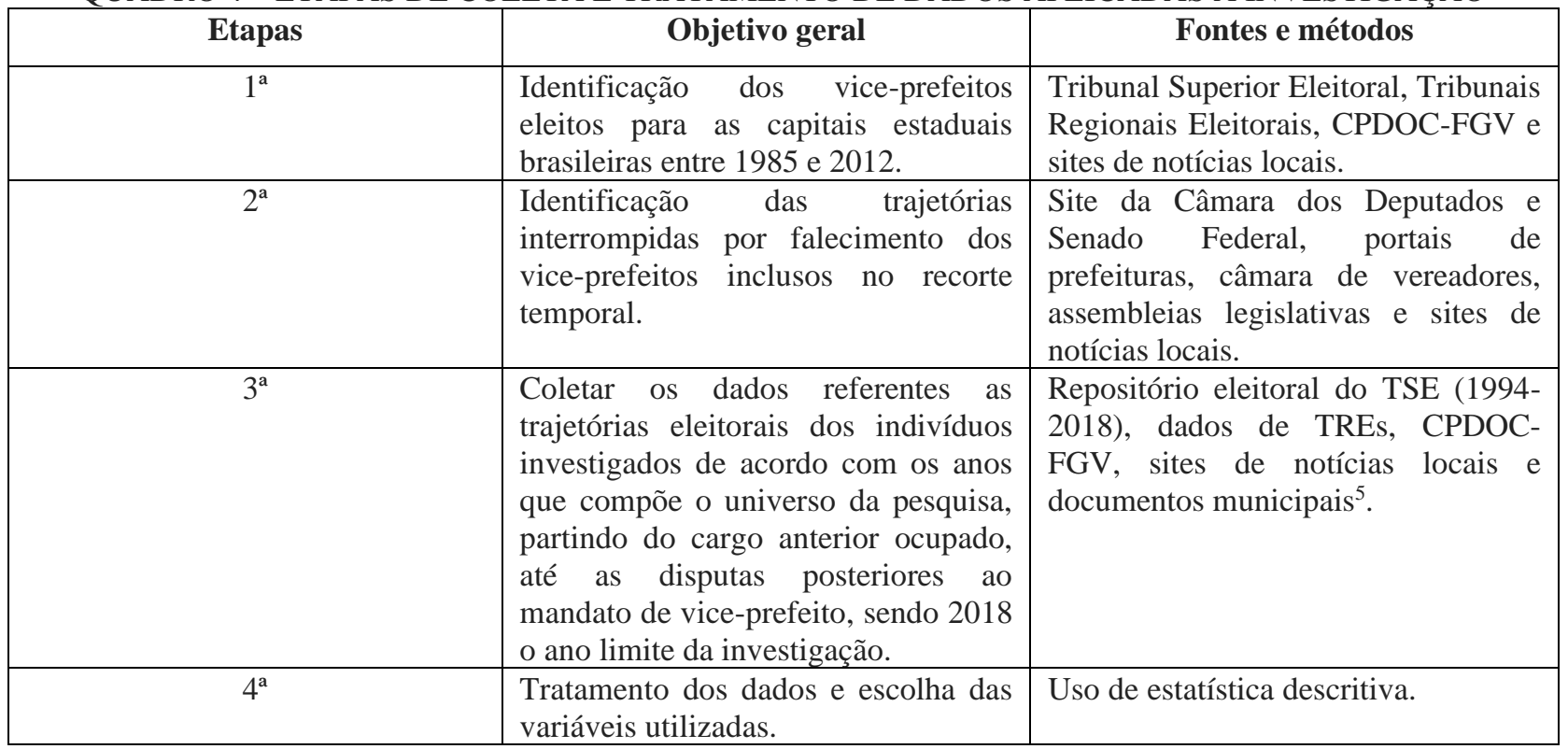

Fonte: Elaboração própria.

A $1^{\text {a }}$ etapa do levantamento de dados, identificou os sujeitos a serem estudados. Aqui verificou-se a repetição de alguns nomes, ou seja, aqueles que foram eleitos mais de uma vez viceprefeito, tanto em períodos alternados (reeleição mediada) e os que - desde a eleição de 2000, com a implantação da reeleição imediata - foram reeleitos. Na prática, para os 206 mandatos de viceprefeito foram eleitos e tomaram posse 191 indivíduos diferentes.

A $2^{\text {a }}$ etapa identificou o falecimento dos vice-prefeitos. A Tabela 1 apresenta o universo exato que a pesquisa alcança, considerando o número de trajetórias completas, ou seja, de 1985 até 2018 e as trajetórias que sofreram interrupção por conta de falecimento.

TABELA 1 - UNIVERSO DA PESQUISA DE ACORDO COM O NÚMERO DE CASOS

\begin{tabular}{lrrrr}
\hline Eleitos & $\begin{array}{r}\text { Trajetórias } \\
\text { completas }\end{array}$ & $\begin{array}{r}\text { Trajetórias } \\
\text { interrompidas }\end{array}$ & $\begin{array}{r}\text { Observações } \\
\text { individuais }\end{array}$ & $\begin{array}{r}\text { Observação } \\
\text { por coorte }\end{array}$ \\
\hline 1985 & 14 & 11 & 18 & 352 \\
1988 & 20 & 5 & 16 & 372 \\
1992 & 20 & 1 & 13 & 300 \\
1996 & 24 & 3 & 11 & 274 \\
2000 & 19 & 1 & 9 & 193 \\
2004 & 21 & 2 & 7 & 149 \\
2008 & 19 & 1 & 5 & 101 \\
2012 & 24 & $\mathbf{3 0}$ & 3 & 74 \\
\hline Total & $\mathbf{1 6 1}$ & $\mathbf{8 2}$ & $\mathbf{1 . 8 1 5}$ \\
\hline
\end{tabular}

Fonte: Elaboração própria.

\footnotetext{
${ }^{5}$ Devido o recorte temporal partir de 1985, algumas eleições estão fora do conjunto de dados disponibilizados pelo TSE. A fim de suprir essas lacunas, foram consultados dados dos Tribunais Regionais Eleitorais (TREs), biografias disponibilizadas pelo CPDOC-FGV, além de portais de notícias locais e documentos municipais.
} 
Já a $3^{\text {a }}$ etapa da coleta de dados traçou as trajetórias eleitorais destes atores, de um lado, os cargos eletivos que ocuparam imediatamente antes de ser vice-prefeito e, de outro, após ocuparem o cargo, além das respectivas candidaturas lançadas e os sucessos e insucessos eleitorais que conquistaram ao longo desses anos.

Resultado da etapa anterior, a $4^{\mathrm{a}}$ etapa foi responsável pelo processo de escolha das variáveis que serão exploradas nesse artigo. Para tratamento e análise desses dados se fez uso de estatística descritiva. As variáveis estão apresentadas no Quadro 5.

QUADRO 5 - VARIÁVEIS DE CARREIRA ELEITORAL PRESENTES NA INVESTIGAÇÃO

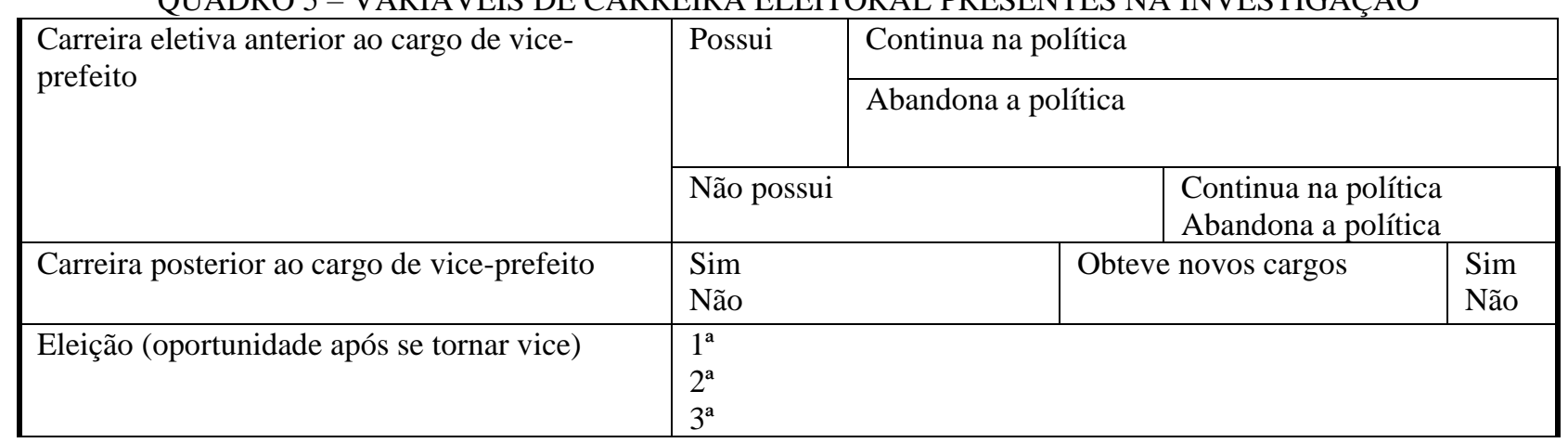

Fonte: Elaboração própria.

As variáveis escolhidas buscaram o objetivo de compreender os padrões de escolha de carreira dos vice-prefeitos das capitais brasileiras. Porém, consideramos não somente as decisões de disputar ou não um cargo eletivo e o momento em que fazem, mas também as direções e ambições políticas que são possíveis revelar através dessas escolhas. Desse modo, olharemos para três outras variáveis: a) os cargos eletivos; b) nível de governo; c) poder político; d) e por óbvio, seus fracassos e sucessos eleitorais nessas disputas.

\section{RESULTADOS E ANÁLISES}

Seguindo a ordem das variáveis apresentadas no Quadro 5, começaremos por revelar as informações referentes as carreiras eletivas anteriores dos atores compreendidos ${ }^{6}$. Com isso, buscou-se descrever se aqueles que se elegem vice-prefeitos das capitais já possuíam experiência

\footnotetext{
${ }^{6}$ Para essa análise considerou-se o universo de 186 personagem. Essa baixa no universo da pesquisa se deve ao fato da falta de informações relativas as carreiras anteriores dos seguintes vice-prefeitos: Antônio Cabral de Castro (Macapá/1988), Eveline Guerra (Natal/1992), Zara Fátima de Oliveira Botelho (Boa Vista/1992), Aldebaro Barreto da Rocha Klautau (Belém/1992), Cláudio Pinho (1992).
} 
em outros postos eletivos antes de chegar ao cargo. A seguir, o Gráfico 1 exibe os resultados referentes as carreiras anteriores dos vice-prefeitos das capitais estaduais brasileiras.

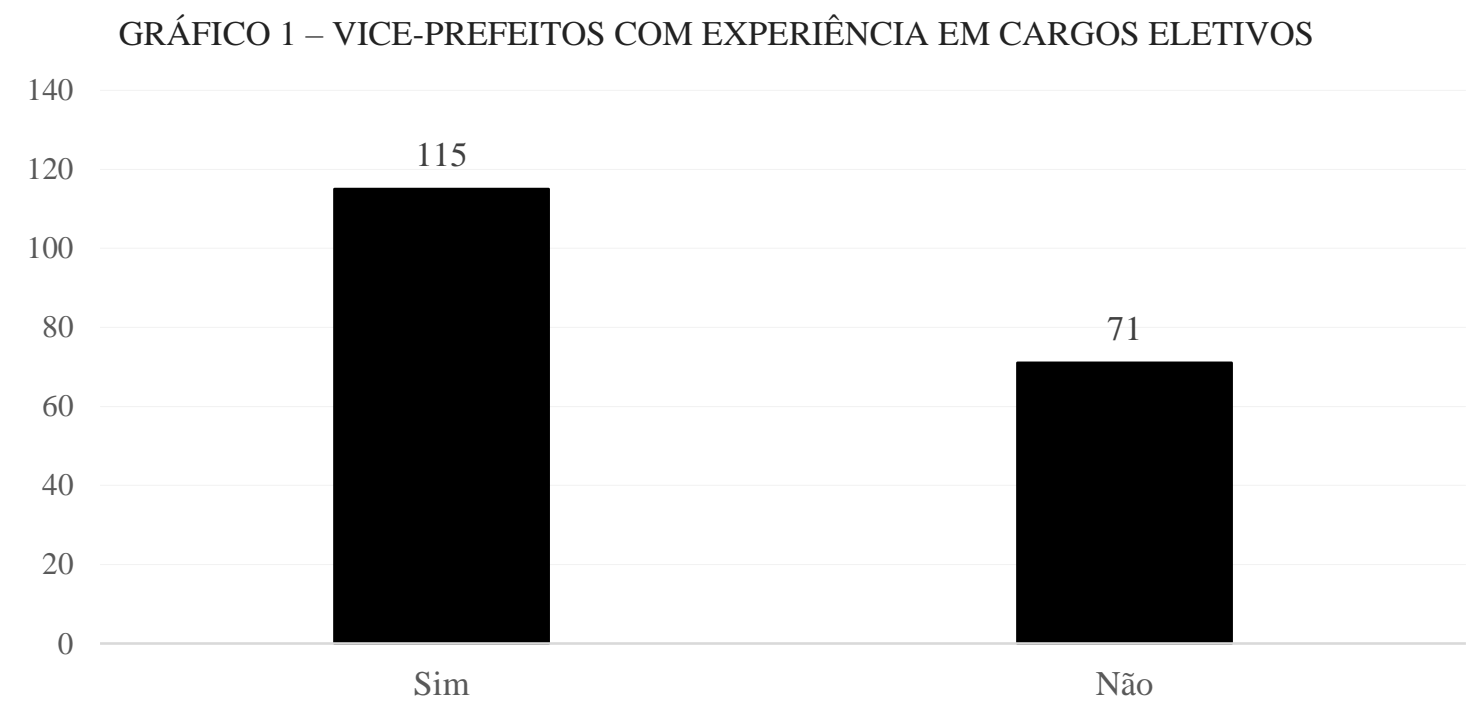

Fonte: Elaboração própria.

Esses dados revelam que $61,8 \%$ dos vice-prefeitos das capitais estaduais brasileiras, antes de chegar ao cargo, já haviam conquistado outros cargos eletivos, enquanto 38,2\% dos indivíduos teve como porta de entrada na carreira política o cargo de vice-prefeito. Com isso, é possível perceber que o cargo de vice-prefeito de capital é na maior parte das vezes um movimento de continuidade na carreira da elite política, não sendo preferencialmente o momento em que resolvem ingressar para a profissão política.

Apesar do sistema político brasileiro possuir uma estrutura de oportunidade flexível, onde a falta de experiência em cargos públicos não é critério para barrar uma candidatura, é possível dizer que as taxas de ingresso por determinado cargo podem revelar algo referente a hierarquia de postos eletivos no país. Segundo Massia (2013), a taxa de ingressantes através do cargo de Governador era de 5\%, enquanto Lima (2017) revela que $36 \%$ dos deputados federais da $51^{\mathrm{a}}$ a $54^{\mathrm{a}}$ legislaturas haviam ingressado na carreira eletiva através do cargo. Assim, é possível indicar que exista uma relação entre o ingresso na política e as taxas de novatos nos cargos.

Sabendo que a maioria do nosso universo utilizou o cargo de vice-prefeito para dar continuidade em carreiras eletivas que já existiam, a nossa próxima análise refere-se à continuidade de carreira desses políticos após a passagem pelo cargo de vice. Para essa análise, consideraremos o universo de 191 trajetórias, no Gráfico 2 estão expostos os resultados. 


\section{GRÁFICO 2 - CONTINUIDADE DE CARREIRA ELETIVA DOS VICE-PREFEITOS}

160

140

120

100

80

60

40

20

0 150

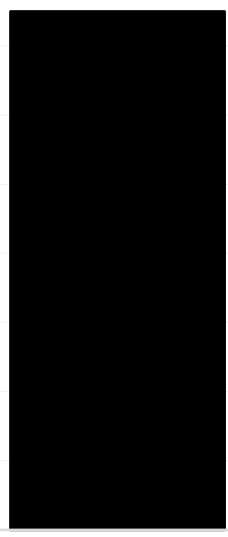

$\operatorname{Sim}$
41

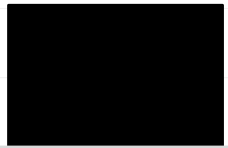

Não

Fonte: Elaboração própria.

Destaca-se que 78,5\% dos vices se dispuseram a competir por novos cargos eletivos após assumir a vice-prefeitura. Já 21,5\% dos analisados retiram-se do jogo eleitoral após passagem pelo cargo. Esses resultados demonstram uma tendência por parte daqueles eleitos para os cargos de vice-prefeitos em buscar prosseguir na profissão política. A fim de comparação, o estudo de Barreto (2017) aponta para que 10,4\% dos prefeitos das capitais acabam abandonando a política, enquanto $89,6 \%$ após o cargo de prefeito buscam dar continuidade. Tais resultados podem estar indicando que existe uma relação entre "grau" de importância do cargo eletivo em uma hierarquia e a ambição por continuar nas competições políticas.

Esses dados revelam que o cargo de vice-prefeito costuma servir para a classe política brasileira como um movimento de carreira que não marca o ponto final de suas trajetórias na profissão política. Nesse caso, seja para aqueles que ingressaram na política ou deram continuidade em suas carreiras políticas, o cargo demonstra ser mais uma etapa dentro da circulação da elite política, servindo para aqueles que desejam continuar no jogo.

A partir desses resultados resta saber de onde vieram esses políticos que buscaram dar continuidade em suas carreiras, ou seja, como escolhem aqueles que já possuíam carreira anterior e como escolhem os ingressantes. Para isso, o Gráfico 3 irá explorar os dados referente as trajetórias anteriores ao cargo de vice-prefeito e as escolhas de continuar na competição política ou retirar-se. 

ELEITORAL

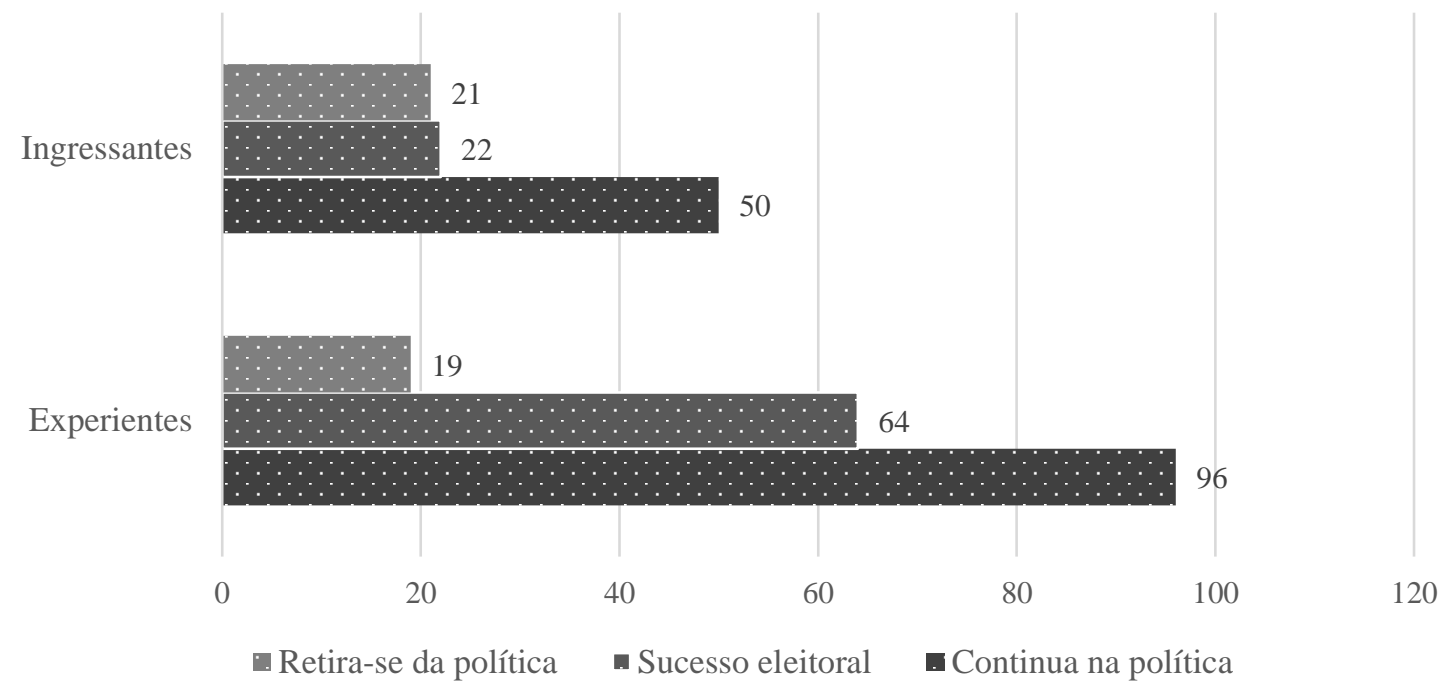

Fonte: Elaboração própria.

Percebe-se que $83,4 \%$ dos que já haviam ocupado cargos eletivos buscam dar continuidade na carreira após a passagem pelo cargo. Já para aqueles que ingressaram na política através do cargo de vice-prefeito, a taxa de continuidade é de 70,4\%, o que corrobora para a afirmação de que o cargo serve como um posto para circulação da elite política. Aqueles que escolhem encerrar suas trajetórias, ou seja, nunca mais voltam a disputar uma eleição é de 16,6\%, e para aqueles que ingressaram a partir do cargo de vice-prefeito, mas optaram por não buscar novos cargos em suas trajetórias é de 29,6\%. Esses dados indicam a existência de maior desejo por continuar na política quando o vice-prefeito já possuía experiências eletivas anteriores. Quando ingressam por meio desse cargo, parece existir maiores condições para a desistência da carreira, ou aquilo que Schlesinger (1966) chama de ambição discreta, significando que esses não demonstram ambição de continuidade e abandonam as competições eleitorais após o final do mandato.

No entanto, o resultado que mais chama a atenção é o sucesso eleitoral posterior dos dois perfis de vice-prefeitos. Nota-se que $66,6 \%$ daqueles que já possuíam carreira eletiva anterior ao cargo voltaram a conquistar pelo menos mais uma vez um novo cargo eletivo em suas trajetórias. Já o sucesso eleitoral daqueles que ingressaram através do cargo de vice-prefeito é de $44 \%$, o que demonstra que o cargo não refletiu em bons resultados eleitorais para a maioria dos vice-prefeitos que eram novatos na profissão.

Seguindo a investigação e na busca por compreender mais acerca dessas escolhas de carreiras dos vice-prefeitos, os próximos passos serão analisar as trajetórias diante das 
oportunidades de disputar novos cargos em meio aos mandatos ( $1^{\circ}$ e $2^{\circ}$ oportunidade) e imediatamente ao final do mandato ( $3^{\circ}$ oportunidade). Com isso, estaremos atentando para os efeitos da estrutura de oportunidades do sistema político brasileiro frente as definições de carreiras políticas, e também em relação aos resultados específicos desses atores. Na Tabela $2^{7}$, contemplaremos as escolhas de carreiras dos vice-prefeitos diante da primeira oportunidade de disputar uma eleição, ou seja, dois anos depois de eleitos.

TABELA 2 - ESCOLHA DE CARREIRA E SUCESSO ELEITORAL DOS VICE-PREFEITOS EM MEIO AO MANDATO

\begin{tabular}{lrr}
\hline Cargo & Candidaturas (N) & ${\text { Sucesso eleitoral }(\%)^{\mathbf{8}}}^{(\mathbf{y})}$ \\
\hline Deputado Estadual & 22 & 68,1 \\
Deputado Federal & 28 & 39,2 \\
Suplente de Senador & 2 & 0 \\
Senador & 14 & 21,4 \\
Vice-governador & 5 & 40 \\
Governador & 6 & 0 \\
Não concorre & 129 & 62,6 \\
\hline Total & $\mathbf{2 0 6}$ & $\mathbf{4 0 , 2}$ \\
\hline Fonte: Elaboração própria & &
\end{tabular}

A primeira informação que a Tabela 2 está revelando é que os vice-prefeitos das capitais optam em 62,6\% dos casos em não abrir mão do mandato em busca de outro cargo eletivo. No entanto, 37,4\% vão em busca de novos cargos eletivos e 40,2\% desses alcançam sucesso, partindo assim em direção a um novo cargo.

O cargo mais ambicionado pelos vice-prefeitos na primeira oportunidade de disputar uma nova eleição é Deputado Federal, seguido pelo cargo de Deputado Estadual. A maior quantidade de tentativas não reflete nos números de sucesso, onde somente $39,2 \%$ dos vices que arriscaram a candidatura rumo ao congresso nacional alcançaram o cargo, enquanto 68,1\% daqueles que foram rumo as assembleias legislativas obtiveram êxito na disputa.

Os cargos de maior relevância e que representam nítidas ambições progressivas como Governador, Vice-Governador e Senador possuem números de candidaturas mais baixos, assim como os respectivos sucessos. Isso indica que ao mensurar os custos e riscos para esses cargos, os vice-prefeitos preferem não arriscar esses rumos.

\footnotetext{
${ }^{7}$ Vale ressaltar que essa análise está voltada aos mandatos, logo, serão realizadas as observações para os 206 mandatos contemplados pelo universo da investigação.

${ }^{8}$ Para cada cargo foi calculada a média de sucesso eleitoral dos vice-prefeitos, para aqueles que optaram por não concorrer é calculada a porcentagem da escolha. Para o total, realizou-se o cálculo da média geral de obtenção desses cargos sob o total de tentativas.
} 
Na Tabela 3 está exposto os dados referentes ao que fazem os vice-prefeitos diante do final de seus mandatos e na eminência de ficar sem cargo eletivo. Para essa análise, saem do banco de dados dois vice-prefeitos que falecem após a primeira oportunidade, o que resulta em um universo de 204 mandatos.

TABELA 3 - ESCOLHA DE CARREIRA E SUCESSO ELEITORAL DOS VICE-PREFEITOS EM FINAL DE MANDATO

\begin{tabular}{lrr}
\hline Cargo & Candidaturas (N) & Sucesso eleitoral (\%) \\
\hline Vereador & 24 & 62,5 \\
Vice-prefeito & 18 & 72,2 \\
Prefeito & 34 & 41,1 \\
Não concorreu & 128 & 62,7 \\
\hline Total & $\mathbf{2 0 4}$ & $\mathbf{5 5 , 2}$ \\
\hline
\end{tabular}

Fonte: Elaboração própria.

Assim como na primeira oportunidade de disputar uma eleição em meio ao mandato, na eleição de final de mandato $62,7 \%$ dos vice-prefeitos resolvem não disputar o pleito. Com isso, 64,2\% dos vice-prefeitos ficaram sem cargos eletivos, já 35,8\% aproveitaram as oportunidades $\left(1^{\circ}\right.$ e $2^{\circ}$ oportunidade) geradas ainda quando ocupavam o cargo de vice-prefeito e deram continuidade imediata em suas carreiras políticas.

Averígua-se que o movimento de carreira mais ambicionado pelos vice-prefeitos é rumo a chefia do Executivo municipal, o que representa um evidente desejo por ambição progressiva. Porém, assim como nas eleições gerais, o cargo de maior relevância das eleições municipais também retém custos e riscos mais elevados, e possui a menor taxa de sucesso eleitoral entre os cargos disponíveis nessa oportunidade.

A busca pela reeleição mediada ou imediata, na qual também poderíamos chamar de ambição estática, como sugere Schlesinger (1966) ao tratar do movimento de carreira, se faz presente com a menor frequência entre as candidaturas dos vices. Porém, o cargo possui a maior taxa de sucesso eleitoral, significando que existem boas possibilidades de reeleição para um viceprefeito.

Por fim, a ambição regressiva, como sugerem Leoni, Pereira e Rennó (2003) para tratar dos congressistas brasileiros, também está presente nos movimentos de carreira dos vice-prefeitos. Com maior frequência do que a busca por ser reeleito vice-prefeito, "descer" para o Legislativo municipal é um movimento frequente e que possui taxas de sucesso elevadas se comparadas com

\footnotetext{
${ }^{9}$ Para cada cargo foi calculada a média de sucesso eleitoral dos vice-prefeitos, para aqueles que optaram por não concorrer é calculada a porcentagem da escolha. Para o total, realizou-se o cálculo da média geral de obtenção desses cargos sob o total de tentativas.
} 
outros cargos de frequência aproximada. Tal movimento de carreira demonstra que a classe política para sobreviver no jogo considera os custos de ir para um cargo que em teoria possui menor prestígio político.

Partindo para última análise em relação as escolhas de carreiras e as oportunidades geradas pelo sistema político, a Tabela 4 apresenta as escolhas perante a terceira oportunidade, onde em teoria, os vices já cumpriram seus mandatos, assim, podem ter acessado novos cargo nas duas oportunidades que passaram ou ficaram livres no mercado eleitoral. Nesse momento, o universo de análise sofre nova redução, chegando a 200 mandatos devido ao falecimento de outros quatro viceprefeitos.

TABELA 4 - ESCOLHA DE CARREIRA E SUCESSO ELEITORAL DOS VICE-PREFEITOS DIANTE DA OPORTUNIDADE IMEDIATA DE PROSSEGUIR CARREIRA APÓS O FIM DO MANDATO

\begin{tabular}{lrr}
\hline Cargo & Candidaturas (N) & Sucesso eleitoral (\%) \\
\hline Deputado Estadual & 38 & 42,1 \\
Deputado Federal & 28 & 35,7 \\
Suplente de Senador & 5 & 20 \\
Senador & 12 & 25 \\
Vice-governador & 3 & 66,6 \\
Governador & 7 & 28,5 \\
Não concorreu & 107 & 53,5 \\
\hline Total & $\mathbf{2 0 0}$ & $\mathbf{3 6 , 5}$ \\
\hline
\end{tabular}

Fonte: Elaboração própria.

Nesse momento, onde os mandatos dos vice-prefeitos já haviam sido encerrados, há uma redução no número de escolhas por não concorrer, o que pode estar indicando que aqueles que haviam sido eleitos na primeira oportunidade estão em busca de possíveis reeleições, mas também pode indicar que um maior afastamento do fim do mandato resulta na busca por novas competições eleitorais.

Os cargos ambicionados também sofrem alterações diante dessa oportunidade. O cargo mais almejado passa a ser Deputado Estadual, enquanto Deputado Federal cai para a segunda posição. O sucesso eleitoral para esses cargos também sofre redução. Essa informação revela que os viceprefeitos quando estão em meio ao mandato conseguem transferir maior capital político para conquistar novos cargos. Além disso, o fato do cargo de Deputado Estadual passar a ser mais ambicionado revela uma possível interpretação dessa elite em avaliar seus custos e riscos na busca por postos de maior relevância, optando assim por passos mais contidos na carreira.

Aqueles cargos que representam nítidas ambições progressivas também sofreram redução nos números de candidaturas, o que vai ao encontro e corrobora para a explicação de avaliação dos 
riscos que os candidatos possuem ao pleitear um cargo mais elevado na hierarquia dos postos eletivos. Nesse mesmo sentido, é possível dizer que os vice-prefeitos conforme vão se afastando de seus mandatos, compreendem haver uma redução de capital político que reduz as chances de obter sucessos para cargos maiores.

As próximas duas análises vão sistematizar por onde buscam circular em relação ao nível de governo e poder político os vice-prefeitos das capitais dos estados brasileiros. No Gráfico 4, atentaremos o poder político mais ambicionado pelos vice-prefeitos e seus respectivos sucessos eleitorais em meio ao mandato e imediatamente após o mandato.

\section{GRÁFICO 4 - PODER POLÍTICO AMBICIONADO E SUCESSO ELEITORAL ALCANÇADO APÓS ELEITO PARA O CARGO DE VICE-PREFEITO}

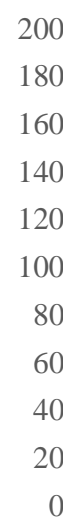

200

180

160

140

120

100

80

60

40

20

0

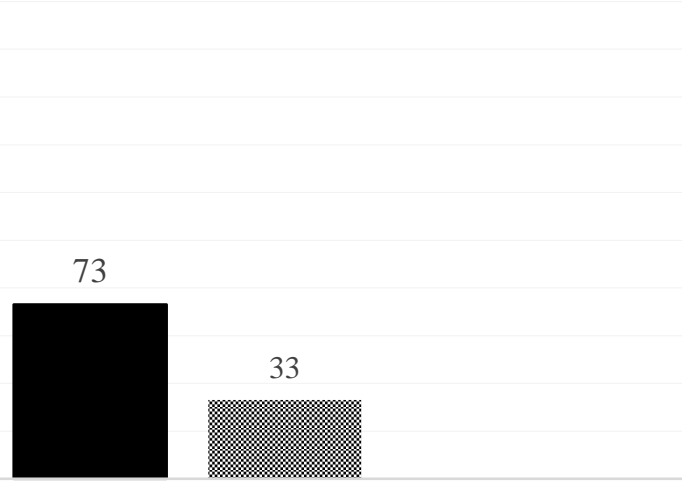

Executivo

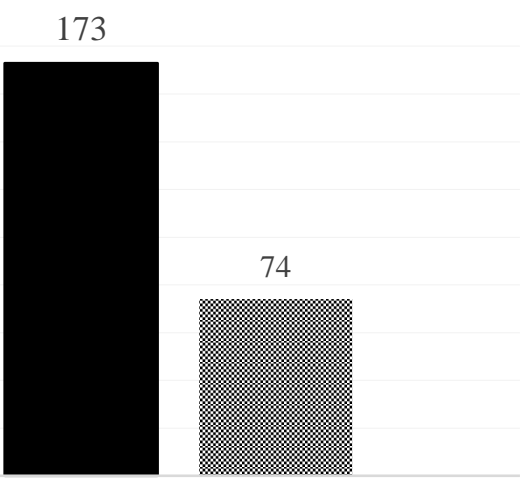

Legislativo

- Candidaturas $\approx$ Sucesso Eleitoral

Fonte: Elaboração própria.

Fica evidenciado o predomínio no número de candidaturas rumo ao poder Legislativo, o que pode ser explicado devido a diversos fatores como: a) maior oferta de cargos por eleição; b) maior facilidade de ser selecionado pelo partido; c) menores custos e riscos para o candidato. $\mathrm{O}$ resultado dessa análise evidencia uma média superior a duas tentativas em direção ao poder Legislativo para uma tentativa ao poder Executivo. Porém, o sucesso eleitoral para essas oportunidades de competição está mais concentrado nos cargos do poder Executivo (45,2\%), enquanto no Legislativo o sucesso eleitoral é de $42,7 \%$. De tal maneira, é possível indicar que a proximidade ao mandato de vice-prefeito é um fator que gera impacto no sucesso eleitoral para cargos do Executivo.

O Gráfico 5 apresenta os resultados referentes aos níveis de governos mais ambicionados pelos vice-prefeitos nas oportunidades analisadas. Com isso, será possível apontar um padrão de direcionamento das carreiras posteriores dessa elite política. 


\section{GRÁFICO 5 - NÍVEL DE GOVERNO AMBICIONADO E SUCESSO ELEITORAL ALCANÇADO APÓS ELEITO PARA O CARGO DE VICE-PREFEITO}

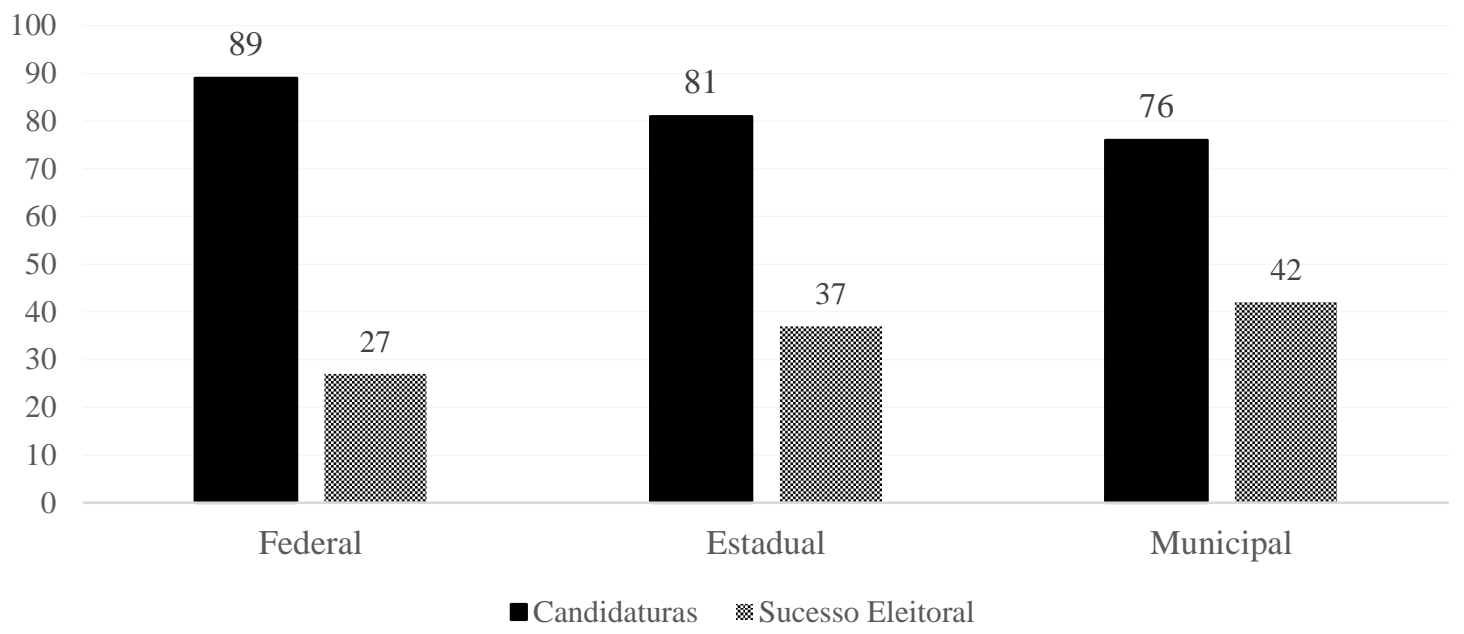

Fonte: Elaboração própria.

O gráfico 5 revela um equilíbrio no número de candidaturas em relação ao nível de governo. Basicamente, o que fica registrado através desse dado é um amplo desejo de circulação da classe política por todos âmbitos de governo. Tal achado, vai ao encontro das evidências trazidas por Borchert (2009; 2011) e Lima (2017) sobre os deputados federais. Devido a estrutura de oportunidades ampla e pouco rígida, é possível que os políticos profissionais façam constantemente movimentos integrados de carreira (BORCHERT, 2009) permeando todos os níveis de governo, algo comum em sistemas multiníveis.

No entanto, os cenários referentes aos sucessos e a concreta circulação dos vice-prefeitos pelos cargos eletivos no país são menores. O sucesso eleitoral rumo ao âmbito federal é relativamente baixo quando comparado aos outros dois, ficando em 30,3\%. Já as buscas por cargos em âmbito estadual possuem 45,6\% de sucesso eleitoral, e no nível municipal em 55,2\%.

Esses resultados retratam o cenário competitivo e incerto que existe na carreira política, principalmente, quando investigamos atores políticos com menor acumulo de capital político. No entanto, o cenário municipal se mostra menos rigoroso do que nos outros dois âmbitos de governo, demonstrando que o capital político da vice-prefeitura parece possuir uma maior transferência e gerar mais impacto quando optam por permanecer no mesmo nível de governo.

\section{CONSIDERAÇÕES}


Retornando a pergunta norteadora dessa pesquisa, é possível realizar alguns apontamentos acerca dos padrões de carreira eleitoral dos vice-prefeitos após o cargo. Reparamos que a maior parte dos investigados já possuíam carreira eletiva antes de alcançar o posto de vice-prefeito. Nessa mesma direção, verifica-se que a tendência dos eleitos é de buscar continuidade na carreira política, sendo assim, é possível afirmar que o cargo costuma ser ocupado por uma elite com experiência em cargos eletivos e ambicionada em continuar suas carreiras eleitorais a partir do cargo de viceprefeito.

Em relação aos movimentos de carreira, nota-se que um sistema integrado, como sugere Borchert (2009), pode ser aplicado para explicar o caso dos vice-prefeitos das capitais do Brasil, visto que diante da análise de três oportunidades de competição política (6 anos) percebe-se uma alta frequência de candidaturas para os três níveis de governo, com predomínio do nível federal, que demonstra ser o rumo mais desejado. Porém, o maior sucesso eleitoral dos vice-prefeitos está em nível municipal, o que indica que o acúmulo de capital político seja transferido nas candidaturas subsequentes ao cargo de vice-prefeito.

O poder político mais desejado pelos vice-prefeitos é o poder Legislativo. O resultado revela os efeitos do sistema político diante das escolhas de carreiras, pois existe uma maior oferta de cargos nesse poder, assim como a competição proporcional de lista aberta (exceto para o Senado Federal), que impacta nos cálculos de custos e riscos das candidaturas, além das maiores chances de serem selecionados pelos partidos políticos do que em competições majoritárias. O sucesso eleitoral mais satisfatório encontra-se nos cargos do poder Executivo, isso devido as taxas de sucesso para reeleição. Mesmo com menores sucessos eleitorais também estão presentes as ambições progressivas, como aqueles vice-prefeitos que buscam o cargo de Prefeito da capital, buscando crescer na carreira no mesmo nível de governo.

Em suma, o estudo busca descrever as escolhas de carreiras dos vice-prefeitos das capitais, compreendendo como ocorrem os movimentos de carreiras no sistema político brasileiro para aqueles que prosseguem na profissão política a partir desse cargo. Por óbvio, o estudo apresenta resultados preliminares e necessita de maiores inferências para ganhar profundidade em relação às análises sobre circulação e ambição política da classe política brasileira. Ademais, parece orientar evidências particulares em relação ao caso dos vices e também atentar para uma agenda de pesquisa relacionada a essas instituições. 


\section{REFERÊNCIAS}

ARAÚJO, Simone. Os poderes Executivo e Legislativo na definição das carreiras políticas no Brasil. 36 ${ }^{\circ}$ Encontro Anual da Associação Anual de Pós-Graduação e Pesquisa em Ciências Sociais. GT 10 Estudos Legislativos, São Paulo, 2012.

BARRETO, Alvaro. Para onde ir? A trajetória eleitoral dos prefeitos das capitais estaduais brasileiras (1996-2014). Opinião Pública, v. 23, n. 1, 2017. Disponível em: <http://www.scielo.br/scielo.php?script=sci_arttext\&pid=S0104-

62762017000100194\&lng=en\&nrm=iso>. Acesso em: 12 out. 2018.

BORCHERT, Jens. Ambition and opportunity in federal systems: the political sociology of political career patterns in Brazil, Germany and the United States. University of Frankfurt, 2009. Disponível em: <http://papers.ssrn.com/sol3/papers.cfm?abstract_id=1450640>. Acesso em: 10 out. 2018.

BORCHERT, Jens. Individual ambition and institutional opportunity: a conceptual approach to political careers in multi-level systems. Regional \& Federal Studies, v. 21, n. 2, 2011.

BORGES, André; SANCHES FILHO, Alvino. Federalismo, coalizões de governo e escolhas de carreira dos deputados federais. Opinião Pública, v. 22, n. 1, 2016.

BRASIL. Constituição. Constituição da República Federativa do Brasil. Assembleia Legislativa, Estado do Rio Grande do Sul, 1988.

COSTA, Luiz; CODATO, Adriano. Reconversão, popularização e ambição: três conceitos sobre as elites parlamentares brasileiras. $\mathbf{1 1}^{\circ}$ Encontro da ABCP, Curitiba, 2018.

FGV. Centro de Pesquisa e Documentação de História Contemporânea do Brasil (CPDOC). Rio de Janeiro: FGV, 2019. Disponível em: <https://cpdoc.fgv.br/>. Acesso em: 15 de maio de 2019.

GRAÇA, Luís. SOUZA, Cíntia. Uso estratégico de eleições alternadas? Efeitos da candidatura para prefeito sobre a votação dos concorrentes ao cargo de deputado federal no Brasil. Revista Opinião Pública, Campinas, v. 20, n. 3, 2014.

KAWASAKA FILHO, Luiz. Contexto histórico. In: Câmara Municipal de Palmas. 22 fev. 2019. Disponível em: <https://www.palmas.to.leg.br/institucional/historia/contexto-historico>. Acesso em: 16 maio 2019.

LEONI, Eduardo; PEREIRA, Carlos; RENNÓ, Lúcio. Estratégias para sobreviver politicamente: Escolhas de carreiras na Câmara de Deputados do Brasil. Opinião Pública, v. 9, n.1, p.44-67, 2003. Disponível em: <http://www.scielo.br/scielo.php?script=sci_arttext\&pid=S010462762003000100002\&lng=en\&nr $\mathrm{m}=$ iso $>$. Acesso em 10 out. 2018. 
LIMA, Rafael. Vereadores candidatos nas eleições para deputado no Rio Grande do Sul (20022010): ambição política, resultados e continuidade da carreira. Dissertação (mestrado em Ciência Política) - Pelotas. Programa de Pós-Graduação em Ciência Política. Universidade Federal de Pelotas, 2013.

LIMA, Iana. Alves de. Carreiras e ambição política em sistemas multinível: um estudo de caso da circulação política no Brasil (1995-2015). Dissertação (Mestrado em Ciência Política) Programa de Pós-Graduação em Ciência Política, Universidade de Brasília, Brasília, 2017.

MALUF, Rui Tavares. A Carreira política na Câmara Municipal de São Paulo (CMSP). 2006. Tese (Doutorado em Ciência Política) - Programa de Pós-graduação em Ciência Política. Universidade de São Paulo, São Paulo, 2006.

MASSIA, Leandro P. A Profissionalização política do poder executivo estadual: uma análise do perfil social e da carreira dos governadores brasileiros (1994-2010). Dissertação (mestrado em Ciência Política) - Pelotas. Programa de Pós-Graduação em Ciência Política. Universidade Federal de Pelotas, 2013.

MIERES, P.; PAMPÍN, E. La trayectoria de los vicepresidentes en los regímenes presidencialistas de América". Revista de Estudios Políticos, n. 167, p. 99-132, 2015.

PEGURIER, F. Carreiras Políticas e a Câmara dos Deputados. 2009. $124 \mathrm{f}$. Tese (doutorado em Ciência Política) - Instituto Universitário de Pesquisas do Rio de Janeiro, Universidade Estadual do Rio de Janeiro, 2009.

SAMUELS, David. Political ambition in Brazil, 1945-1995: Theory and evidence. Meeting of the Latin American Studies Association, Chicago, 1998.

SAMUELS, D. Ambition, Federalism and Legislative Politics in Brazil. Cambridge: University Press, 2003.

SANTANA, Luciana. Perfil, trajetórias e ambição política dos legisladores na construção de suas carreiras: Argentina, Brasil, Chile e Uruguai. Teoria \& Sociedade, v. 16, n. 2, 2008.

SANTOS, Fabiano. Recruitment and Retention of Legislators in Brazil. Legislative Studies Quarterly, v. 24, n. 2, 1999.

SANTOS, Fabiano; PEGURIER, Fabiano. Political Careers in Brazil: Long-term Trends and Crosssectional Variation. Regional \& Federal Studies, v. 21, n. 2, 2011.

SARRAFERO, Mario. El poder y su sombra. Buenos Aires: Editorial de Belgrano, 1999.

SCHLESINGER, Joseph. Ambition and politics: Political careers in the United States. Chicago: Randy McNally. 1966.

UGGLA, F. The politics of vice-presidential selection in Latin America. Electoral Studies, n. 65, 2020. 